\title{
Complexity, Structured Chaos and the Importance of Information Management for Mobile Computing in the UK Floods of 2007
}

\author{
Christopher W. Johnson \\ Department of Computing Science, University of Glasgow, \\ Glasgow, Scotland, G12 8RZ, UK. \\ johnson@dcs.gla.ac.uk
}

\begin{abstract}
Many research teams have developed mobile computing architectures to support the emergency and rescue services in a range of civil contingencies. These proposals are based on innovative technologies and show considerable creativity in the design of their user interfaces. In contrast, this paper presents lessons learned from the 2007 UK floods. Mobile telecommunications failed in many different ways and from many different causes, including physical damage to handsets, as well as the loss of base stations and UPSs. The insights gained from the floods are being used to inform the design of next generation mobile digital communications systems for UK responders. However, the technical problems are arguably less important than the insights that were obtained about 'systemic' failures in the interfaces between local government, emergency services and the variety of agencies that must cooperate in major civil contingencies. Problems in information management led to inconsistencies and incompatibilities. In consequence, the output from one application could not easily be used as input to systems operated by other agencies. These issues must be addressed before we are overwhelmed by the increased bandwidth afforded by new mobile devices and novel sensing technologies. It is concluded that unless we understand the chaos, complexity and the contextual issues that characterise previous emergency situations then there is little prospect that we will be able to design effective mobile technologies for future incidents.
\end{abstract}

Keywords: accident analysis; national critical infrastructures; mobile devices.

\section{Introduction}

There have been a number of innovative proposals for the application of mobile computing technologies to support the emergency services. These include systems that focus on small teams of co-workers [1] as well as those that support large distributed organizations [12]. They include applications that provide structured interfaces to mobile systems for emergency workers [13] as well as less formal networking applications that support diverse group of end-users [10]. Other research teams have extended conventional evaluation techniques from desktop systems to support the validation of human-computer interaction with mobile devices by teams of emergency workers [4]. Other groups have extended ideas from pervasive and ubiquitous computing [2] ; including the development of 'wearable' devices to 
support interaction with computational infrastructures during emergency situations [6].

\subsection{Strengths of Mobile Systems in Civil Contingencies}

Most of these initiatives are based on the assumption that mobile computational systems provide significant value beyond traditional voice communication applications [9]. Mobile systems can be used by emergency personnel 'on site' during a contingency to navigate across multiple information sources held by different government and commercial agencies. This flexibility is critical when data cannot easily be formatted or structured in a way that will support the detailed requirements of every potential emergency. PDAs and similar devices provide a common interface to a vast array of information resources, including but not limited to census data, medical records, hazard information (e.g., flood predictions, location of hazardous substances etc), and weather details. Mobile computer systems can be integrated with digital telecommunications infrastructures to provide real-time updates as information becomes available. They can reduce the need to manually update paper-maps with the changing locations of emergency crews and with information about potential casualties. Images of an emergency can be communicated back from mobile devices on the scene of a civil contingency to help improve the situation awareness of coworkers and of coordinators in remote locations.

\subsection{Concerns about Mobile Systems in Civil Contingencies}

Changes to the technological infrastructure of complex systems cannot be 'risk free' [5]. The provision of new services creates new hazards, for example when users have to cope with the failure of services normally provided using mobile technology. Further problems arise when mobile systems are poorly integrated into existing working practices. The UK Independent Police Complaints Commission (IPCC) recently described how the driver of a marked police car was responding to the activation of his vehicle's automatic number plate recognition system, when a pedestrian was hit and killed [3]. Similarly, the US National Oceanic \& Atmospheric Administration (NOAA) released a warning in 2002 about some of the systemic effects of GPS on navigation behavior. These warnings were addressed to all users of mobile devices including emergency personnel. NOAA went on to point out that the increasing accuracy of GPS exposes underlying problems in the accuracy of charts. Many maps were developed using less accurate fixes than those provided using GPS technology. It was argued that prudent users should employ "the utmost caution, no matter what navigational method is used" [8].

\subsection{Overview of the Paper}

The following pages collect together a number of lessons that were learned about the application of mobile technologies from the 2007 UK floods. These included insights about the vulnerability of the mobile telecommunications infrastructures that support many of the technical innovations proposed in previous studies. The floods also revealed 
underlying problems in information management that frustrated attempts to coordinate data exchange between different agencies.

Other insights included the importance of helping members of the public to access information from a wide range of sources, ranging from local government to the police, from insurance companies to utility companies. In many cases, individuals and families had a range of existing devices that could have provided access to critical information even though there were problems with the telecommunications infrastructure. Many failed to find the details that they needed to protect themselves and their family because the information was not structured in a way that could easily be downloaded onto available devices. Critical data was often scattered over different web sites or between on-line resources and through telephone 'hot lines'. It is concluded that we must develop a more coordinated approach to information management in order to design mobile technologies that can be used by emergency personnel and the general public in future contingencies.

\section{The Scale of the Floods and the Need for Mobile Resources}

Many areas of the United Kingdom experienced their heaviest rainfall since records began between May and July 2007. Precipitation exacerbated high levels of ground water. This combination overwhelmed drains and other forms of flood defence. The UK Meteorological Office recorded $414.1 \mathrm{~mm}$ of rain across England and Wales; this is over double the mean level of rainfall expected during this period. The most severe floods occurred across Northern Ireland on 12th June; East Yorkshire and areas of the Midlands on 15th June; Yorkshire, Gloucestershire and Worcestershire on 25th June; and Oxfordshire, Berkshire and South Wales on 20th July. The independent report into the subsequent floods, chaired by Sir Michael Pitt [11], argued that these events created "a new level of challenge" for emergency personnel; triggering "a series of emergencies which stretched local resources to the limit" and which provided UK civil contingency planners with a "wake-up call".

\subsection{Impact on the Transportation and Supply Infrastructures}

The consequences of the floods are difficult to exaggerate. They continue to affect the lives of many families that were caught up in them. This natural civil contingency has been linked to 13 deaths as well as damage to over 40,000 homes and 10,000 businesses. In some places, the floodwaters rose over a number of hours. In other areas, emergency service personnel and members of the public were left stranded as flood defences failed and roads were closed. Five hundred people were left on the platforms and concourse areas of Gloucester railway station on the night of the $20^{\text {th }}$ July as areas of the UK national rail network were disabled. At the same time, approximately 10,000 motorists were stranded by the closure of Junctions 10 to 12 on the M5 motorway. The interruptions to transportation infrastructure had knockon effects for the logistics of recovery operations as food, oil and personnel had to be re-routed to take account of successive closures across the transportation networks. 


\subsection{Impact on the Water Infrastructures}

The coordination of civil contingencies in the UK is divided between three levels. Bronze describes the operational management of an incident usually on-site. Silver level refers to tactical management; operating remotely providing the resources to implement pre-determined contingency plans. Gold command defines the overall strategy for resolving an incident and coordinates recovery actions. The Pitt interim report describes how Gloucestershire Gold Command group convened around 18:00 on Friday, $20^{\text {th }}$ July 2007 [11]. The Environment Agency reported that they did not expect any significant river flooding. The same evening, the Meteorological Office warned that heavy rain was expected to continue overnight. The Gold Command held a teleconference to review the situation around 10.30 on Saturday 21st July. The Environment Agency again said that it expected little or no serious flooding. In consequence, a further meeting was held at 18:00 before the Gold command group disbanded for the evening. During the early hours of the $22^{\text {nd }}$, the Mythe water treatment works was shut down by rising flood water and serious flooding occurred in urban areas. The Gold command group was hastily reconvened. Water supplies in the area were not declared fit again until the $7^{\text {th }}$ August. A collection of agencies responded to this and similar problems across the flooded areas, including the Army and the Red Cross. However, it is estimated that in several areas it was only possible to provide 10 litres per person per day well short of the 15-20 litres recommended by the World Health Organisation [11]. Members of the public were engaged in increasingly frantic searches for drinking water.

\subsection{Impact on the Power Infrastructures}

Rising levels of ground water also began to affect the integrity of dams, for example at Ulley reservoir, near Rotherham. This posed considerable risks both for the local population and for a host of other infrastructure assets. Such effects were only part of wider disruption across the electricity distribution networks. On $23^{\text {rd }}$ July, the loss of the Castle Meads sub-station affected approximately 42,000 people in Gloucester. In Yorkshire, 4 major sub-stations and 55 secondary sub-stations were flooded causing more than 130,000 people to lose their supply. Similarly, the Walham switch station provided an interface to the UK high-voltage network for almost 500,000 people across Wales and Gloucestershire. As the waters from the River Severn rose, it became clear that this major infrastructure component was at significant risk. Members of the fire and rescue service, the Armed Forces, the Environment Agency and the National Grid assembled defences that eventually prevented the loss of the station. A previous risk assessment had assessed the risk of flooding for this site to be 1 in 1,000 per annum, an estimate that has been raised in 2005 to between 1 in 75 and 1 in 200 [11]. 


\subsection{Impact on the Telecommunications Infrastructures}

Telecommunications companies suffered considerable losses as floodwater began to infiltrate critical equipment. Further damage was caused by soil erosion and consequence cable breakages. Knock-on effects propagated from the loss of mains supplies as mobile base stations were forced rely on Uninterruptible Power Supplies (UPS). Backup generators began to run short of fuel and battery based systems were lost after a few hours. Internet routers were affected in a similar manner. The consequences were compounded by the numbers of users competed for remaining bandwidth in order to transfer critical digital information and to remain in contact with co-workers or family members. The effects of these interruptions were, however, mitigated by local Internet Service Providers who made ad hoc arrangements using borrowed generators and rerouting facilities to offer limited access for some users in the affected communities.

\section{Mobile Response and the Emergency Services' Perspective}

In retrospect, many telecommunications companies were surprised by the resilience of networks that continued to function even in areas of considerable flooding. The increasing use of optical fibre rather than copper cabling partly helps to explain why some communities were able to access digital infrastructures. The floods also reinforced the need to bring telecommunications and energy infrastructure managers into Gold command at an earlier stage in order to help coordinate the defence of both conventional and mobile infrastructures.

\subsection{Demonstrating the Potential of Mobile Digital Technologies}

Other lessons focussed more narrowly on the deployment of mobile telecommunications infrastructures. Gloucestershire Fire and Rescue Service's Incident Command Unit (ICU) used satellite communications to enable Internet access during July 2007. The ICU initially provided a central point of reference for the public but had to be redeployed as priorities changed. It was moved to coordinate the defence of the Castel Meads station, mentioned above. This redeployment is instructive because it shows how mobile resources can be moved to meet the changing priorities of civil contingencies. The redeployment of the Gloucestershire ICU also illustrates the benefits of mobile systems that can be used to satisfy multiple roles - both in supporting the general public and also in coordinating the response of emergency personnel.

The floods also illustrated the benefits of a new generation of digital telecommunications systems, such as Airwave. Many of these applications provide multiple levels of redundancy so that voice communication can be maintained even when elements of the underlying infrastructure have failed. Networks of base stations provided a technical backbone that enabled police to communicate with other emergency services over a common network. However, the floods reiterated the limitations of voice communications systems during civil contingencies. There were 
many situations in which emergency responders reported the need to transfer images or other documents that might have avoided lengthy discussions over devices with finite battery power. In particular, problems arose when emergency services tried to request support from neighbouring organisations. Direct voice messages asking for assistance had to be forwarded up the chain of command until they were relayed to officers and management staff with sufficient authority to approve the request. This led to frustration and delays especially when requests were refused. This occurred, for example, when neighbouring Fire and Rescue Authorities' were themselves struggling to secure necessary resources ranging from sandbags to drinking water or high volume pumping equipment.

At the time of the floods, several projects were underway to automate requests for support using digital data exchange. The UK FiReControl project is intended to provide firefighters with data terminals on their vehicles that can present a wide of information, including mapping and incident data, through a standard interface [7]. Similarly, the Firelink project will deliver a digital radio network for the Fire and Rescue Services (FRS) in England, Scotland and Wales that can be interoperated with all Fire and Rescue Authorities and with other emergency services. However, these facilities were not widely available across all of the FRS' involved in the immediate response to the 2007 floods. Even those authorities that had digital communications did not have sufficient devices for their needs.

The UK Chief Fire and Rescue Adviser's review also argued that the floods helped to highlight the differences in terms of the technology that was currently available in Fire and Rescue Services control rooms [7]. Mobile data capability is available 'at some level' in just over half of the 46 Fire and Rescue Authorities. Only two use it for the 'mobile scenarios' envisaged by the FiReControl project. Nine more have the capacity to support Mobile Data Terminals but there are strong differences in the ways that the systems will be used. Organizational and political barriers have created a situation in which there is no national capability to mobilize the nearest appropriate resource regardless of ownership.

\subsection{Organizational Barriers to the Effective Use of Mobile Telecommunications}

The floods of 2007 highlighted the non-technical problems that complicate the deployment and operation of mobile computer systems. Subsequent enquiries have considered how projects, such as FiReControl, could enable users to request assistance from neighbouring agencies [7]. In particular, attention has focused on the protocols that might enable a member of the Fire and Rescue Service at the scene of an incident to ask for additional resources from a Remote Control Centre (RCC). This centre could be tens or hundreds of miles from the scene of any contingency. One proposal being considered by the FiReControl project enables one centre to automatically detect when another, local RCC could no longer cope with the demands being placed on it. The Remote Control Centre might then mobilise resources that would normally be under the control of the local centre. Such scenarios are not normally the focus of mobile systems research. Most previous work focuses on technical infrastructures or user interface characteristics. However, these proposals create significant concerns for local centres who must maintain sufficient situation 
awareness to recognise when some of 'their' resources have been redeployed by the remote intervention of another RCC.

In contrast, Gloucestershire Fire and Rescue Authority reported that having Gold Command bases close to the local mobilising centre had 'significant operational benefits'. They were also 'concerned about how this would work once the Remote Control Centre was in place' [7]. The meta-level point here is that unless the research and development community pay close attention to the insights from previous contingencies then there is a danger that we will develop systems which do not address the concerns of operational staff with first-hand experience in trying to manage the 'structured chaos' and the complexity of real-world events.

In the UK, there is a distinction between category 1 and category 2 responders. The former include the Police, Fire and Rescue Services, Emergency Medical Services, the Coastguard, Local Authorities, Primary Care Trusts, Acute Trusts, Foundation Trusts etc. Category 2 responders include Electricity Distributors and Transmitters, Gas Distributors, Water and Sewerage companies, Telephone service providers (fixed and mobile). They also include the transport sector, including Network Rail, Train Operating Companies (passenger and freight), Underground companies, the Highways Agency, Airport operators etc. The floods illustrated considerable problems in coordinating the activities of category 1 and 2 responders. Many category 2 agencies were unaware of the procedures and protocols used by Gold Command and hence found it difficult to contribute in the manner that had been anticipated. Further problems arose from the confusion over the lead agency for dealing with floods. At the time of writing this paper, the precise division of responsibilities between Fire and Rescue Services, the Maritime and Coastguard Agency, the RNLI, river police etc is unclear. This lack of clarity complicates future inter-agency cooperation, which in turn, has the potential to undermine the benefits of technical innovation through the deployment of mobile systems.

The ability to communicate during contingency is facilitated by the provision of mobile technologies. However, many category 2 groups are not covered by the mobile infrastructures identified in previous sections of this paper. Many of them have no means of accessing the digital communications infrastructures available to the category 1 responders. This creates significant barriers to the 'seamless' transmission of digital information that many people have anticipated. The use of the name 'Firelink' to describe the digital radio network for the Fire and Rescue Services (FRS) illustrates some of the design assumptions behind these infrastructures. Applications that have been developed primarily to support the response to fires cannot always be redeployed for use in flood rescues from inflatable dinghies. Similarly, there can be significant inter-operability issues between this new generation of digital communications infrastructure and the wider stakeholders in any response to civil contingencies.

\subsection{Information Management Barriers to the Use of Mobile Digital Telecomms}

The organisational issues that complicated the response to the 2007 floods were exacerbated by a number of concerns that had not been anticipated during contingency planning. Many of these issues stemmed from legal 'myths' about civil 
liberties. This aspect is also often overlooked by the proponents of mobile systems but was a significant issue for many of the agencies involved in the flood response. Members of the Fire and Rescue Services were tasked to offer assistance to the elderly and to other 'at risk' groups in the communities affected by the rising waters. However, in order to find the addresses of people who might need help, they were forced to consult local healthcare organisations, self-help groups etc. Many of these agencies were unwilling to release personal details of their clients even under during severe flooding. Individuals felt that by disclosing this data they would be liable under European human rights legislation and the UK Data Protection Act. Cabinet Office guidance makes it clear that public safety overrides many of these concerns during civil contingencies. However, this message did not reach many of the emergency workers in the field.

The 'myths' surrounding the UK Data Protection Act form part of a wider pattern of confusion, contradiction and inconsistency that characterised many aspects of the information interchange that took place between local and national agencies during the floods. It is to be hoped that the proposed mobile computational systems will address many of these problems. However, there is a considerable risk that Gold and Silver commands will be overwhelmed by the data from the proposed new generation of handheld data terminals. Conversely, there is a risk that few category 1 responders will have time to use many of the facilities offered by these mobile systems.

The UK Cabinet Office had an almost continual need for information from local agencies to help form the 'big picture' during the floods of 2007. Some Gold and Silver commands were swamped by requests for information. At the same time, many were focused on acting at a local level. They often did not prioritise these requests from national agencies if they were not perceived to directly help the people caught up in local flooding. The extent of the confusion can be illustrated by the difficulty that central government faced in determining how many people had been affected by the June floods. Initial reports from the Environment Agency suggested that between 3,000 and 4,000 properties were affected [11]. Several days later, Government Offices and local authorities reported that 30,000 houses were flooded. The discrepancy arose because the Environment Agency only counted properties affected by river flooding. It excluded surface water flooding of urban properties that was the most significant source of damage during June 2007. These differences create enormous problems that cannot easily be addressed through the introduction of mobile computing devices unless they are accompanied by a root and branch reform of the information management systems across national and local government.

Not only did central government receive a confused picture from local agencies, those agencies themselves had a "poor understanding of the location of critical sites; the mapping of their vulnerability to flooding; the consequences of their loss; and dependencies on other critical infrastructure' [11]. There was a need for first responders to have up-to-date flood risk information to coordinate their efforts in helping the public. This data was also important to ensure that emergency personnel did not expose themselves or their vehicles to additional hazards. Such risk assessments create a requirement to integrate meteorological forecasting, with environmental and urban models that consider critical infrastructures. Responders must also be able to access warnings issued by many other agencies, for example to ensure that they are aware of changes in the level of a water course, or to determine 
whether or not a power cable is live, or to determine the degree of risk posed by structural damage to a dam. None of these issues directly related to the development of mobile computational infrastructures. Those agencies that deployed the new generation digital systems reported considerable satisfaction, although there were some caveats about the need for more devices and more robust user interfaces [7]. The real problems stem from the institutional and organisational barriers to information interchange. For example, different government agencies used different mapping systems. This made it difficult to share data - for instance about flood levels and the location of 'at risk' members of the public or the location of Fire and Rescue Personnel and the state of local critical infrastructures. In the aftermath of the floods, it was proposed that the "use of flood related data on Mobile Data Terminals as part of the FiReControl/Firelink projects should be considered' [7]. Only with the benefit of hindsight can we argue that such requirements should have been central to the initial design of any future mobile system for national civil contingencies.

\section{Mobile Response and the General Public's Perspective}

Previous paragraphs have focused on the mobile infrastructures from the perspective of emergency workers. We have ignored the information requirements of the families and individuals that were caught up in the floods. The Pitt review describes how one family saw water pour through the door of their home [11]. They asked the council for sandbags, which arrived one week later and after their property had sustained significant damage. When he called the Fire and Rescue Service, the father was put through to a different county. We have already described how the FireControl and similar projects are planning to support this load balancing do that one authority can aid another. In this case, however, the neighboring Fire and Rescue Service was not able to provide help. The home owner was concerned that the water in his house was contaminated and so decided to move. The council told him to go to a local leisure center - he drove his family at some risk through the flood waters only to find that had been given the wrong information. It was not being used as a rest center.

It is important to look at the wider 'systems level' issues that prevented the dissemination of information to the public. The loss of mains power in many areas disrupted the use of mains radios, televisions, computers and fixed line telephones. Problems with routers and with mobile base stations gradually began to affect other forms of portable telecommunication. However, information was still conveyed using door-to-door calls to vulnerable people; sirens, loudhailers, PA announcements [7, 11]. Previous sections have also stressed that many aspects of the infrastructure were surprisingly resilient and so many members of the public received information using electronic messages on motorways; automated telephone messages, fax, email, SMS texts; television and radio.

Ad hoc combinations of the existing communications channels were used to convey critical information to the public in the same way that emergency personnel found ways to 'work around' problems in their mobile and fixed telecommunications infrastructure. A key lesson learned from the 2007 floods for informing both the public and emergency responders was that the technology was arguably less important 
than the message itself. Just as the Fire and Rescue Services found difficulty in interpreting the risk assessments and warnings from other agencies, so also the general public had great problems in using the information that was eventually passed to them. One businessman noted that "The websites don't actually say Tesco's car park is going to flood - it's this tributary and that confluence - for people who don't have a geographical knowledge of rivers, it's almost impossible to weigh what's at threat and what's not" [11].

The lack of integrated information management systems affected the public as much as they did category 1 and category 2 responders. Individuals were forced to search through dozens of web sites to find information about insurance claims, about whether or not they could drink the water in their mains supply, about the disconnection or restoration of electricity; about the risk of further flooding. These sites were usually overloaded with enquiries and response times were very poor. This led to further frustration. "The thing that I found most difficult, as a company trying to keep 34 people going, and in the end we relied on Severn Sound (a local radio station) and the website, was to find out what was the truth about water. Can you drink it? Can you use it in the dishwasher? Can you boil it? They didn't know and they said first it wasn't drinkable" [11]. The provision of advanced mobile computational infrastructures is only one small part of the wider set of measures that are required to ensure that the public are never again left in such uncertainty over basic information requirements in the aftermath of civil contingencies.

\section{Conclusions and Further Work}

This paper has presented a number of lessons learned from the 2007 UK floods. Mobile telecommunications failed in many different ways. There were problems with using handsets that were designed to be operated in vehicles or on foot as emergency personnel struggled to reach families and individuals in dinghies or by wading through water. Other failures were caused by battery failures as the floods persisted over several days. Some agencies had access to newer forms of digital communication, including AirWave. However, they did not have enough devices to support the range of operations they were being expected to perform. These issues were compounded by failures in less resilient communications infrastructures, caused by the loss of base stations and UPSs. Such problems particularly affected coordination between category 1 responders and the category 2 groups, which are often overlooked during the deployment of more resilient mobile communications systems.

These technical issues are arguably less important than the insights that were obtained about 'systemic' failures in the interfaces between local government, emergency services and the variety of agencies that must cooperate in major civil contingencies. In particular, problems in information management led to inconsistencies and incompatibilities both at the level of individual data items, including assessments of the number of properties affected, and at the systems level, for instance between the data format used by Geographical Information Systems. In consequence, the output from one application could not easily be used as input to systems operated by other groups of responders. These issues must be addressed before we are overwhelmed by the increased bandwidth afforded by new mobile computing devices and novel sensing technologies. Unless we understand the chaos, complexity and the contextual issues that characterise previous emergency situations then there is little prospect that we will be able to design effective mobile technologies for future contingencies. 
Acknowledgments. Thanks are due to the members of the Pitt review team whose work has motivated and informed the argument in this paper.

\section{References}

1. Auriol, E., AMIRA: Advanced Multi-modal Intelligence for Remote Assistance, Mobile Response, Springer Verlag, LNCS Volume 4458/2007, 51-60.

2. Baber, C., Cross, J., Smith, P. And Robinson D., Supporting Implicit Coordination Between Distributed Teams in Disaster Management in Löffler, J. and Klann, M. eds. Mobile Response 2007, LNCS 4458, Springer, 2007, 39-50.

3. BBC New, Arrests follow police car death, 21 May 2008, Available from http://news.bbc.co.uk/1/hi/england/tyne/7410441.stm, Last Accessed 23 ${ }^{\text {rd }}$ June 2008.

4. Chittaro, L., Zuliani, F. and Carchietti, E. Mobile Devices in Emergency Medical Services: User Evaluation of a PDA-based Interface for Ambulance Run Reporting. in Löffler, J. and Klann, M. eds. Mobile Response 2007, LNCS 4458, Springer, 2007, 20-29.

5. Johnson, C.W., A Handbook of Accident and Incident Reporting, University of Glasgow Press, Glasgow, 2003. Available to download from: http://www.dcs.gla.ac.uk/ johnson/book, last accessed $24^{\text {th }}$ June 2008.

6. Klann, M. Playing with Fire: User-Centered Design of Wearable Computing for Emergency Response. in Löffler, J. and Klann, M. eds. Mobile Response 2007: Mobile Information Technology for Emergency Response, LNCS 4458, Springer, 2007, 116-125.

7. Sir K. Knight, Facing the Challenge: The Chief Fire and Rescue Adviser's review of the operational response by the Fire and Rescue Service to the widespread flooding in England during 2007, Department for Communities and Local Government, London, UK, March 2008.

8. National Imagery and Mapping Agency, Using Nautical Charts with Global Positioning System, edition 2. Available to download from: http://www.geocomm.com/channel/gps/news/nimagps $2 /$, last accessed $24^{\text {th }}$ June 2008.

9. NRC: Summary of Workshop on Using Information Technology to Enhance Disaster Management. The National Academics Press, Washington, DC (2005)

10. Palen, L., Hiltz, S.R. and Liu, S. Online Forums Supporting Grassroots Participation in Emergency Preparedness and Response. Communication of the ACM, 50 (3). 5458.

11. Pitt Review learning Lessons from the 2007 Floods (Interim report), Cabinet Office, London, UK, December 2007.

12. Van Den Eede G, Van de Walle B (2005) Operational risk in incident management: a cross-fertilisation between ISCRAM and IT governance. In: Van de Walle B, Carle B (eds) Proceedings of the 2nd international conference on information systems for crisis response and management ISCRAM2005, pp 53-60

13. Waldher, F. , Thierry, J., and Grasser, S., Aspects of Anatomical and Chronological Sequence Diagrams in Software-Supported Emergency Care Patient Report Forms, Mobile Response, Springer Verlag, LNCS Volume 4458/2007, 9-18. 